\title{
ANTIHYPERLIPIDEMIC ACTIVITY OF Cucumis melo L ON HEXAVALANT CHROMIUM INDUCED MALE ALBINO RATS
}

\author{
${ }^{1}$ G. Malathi1, J. Vadivelu*2 and S. Rajeshkumar ${ }^{3}$ \\ ${ }^{1}$ Research Scholar, Post Graduate and Research Department of Biochemistry, \\ Sri Akilandeswari Women's College, Wandiwash 604 408, Tamil Nadu, India \\ ${ }^{2}$ Assistant Professor,Post Graduate and Research Department of Biochemistry, \\ Sri Akilandeswari Women's College, Wandiwash 604 408, Tamil Nadu, India. And \\ ${ }^{3}$ Nanobiomedicine lab, Department of Pharmacology, Saveetha Dental College and Hospitals, Saveetha University, \\ SIMATS, Chennai-600077, TN, India \\ *Corresponding Author: J. Vadivelu
}

\begin{abstract}
CHROMIUM $(\mathrm{Cr})$ is a natural heavy metal, found in different forms such as $\mathrm{Cr}$ III and Cr VI. The Cr VI (hexavalent $\mathrm{Cr}$ ) is the most common forms and otherwise termed as potassium dichromate ( $\mathrm{K} 2 \mathrm{Cr} 2 \mathrm{O} 7)$, which is generally located in the brownfields, public distribution water systems, surface and subterranean waters throughout the industrialized world. The exposure of Cr VI in these areas may causes tissue damage (testis, spleen, kidney and liver). Our present study to focussed to work with liver and kidney tissues. Therefore, the injuries of renal and hepatic tissues are crucial for altering the lipid profiles on the exposure of $\mathrm{Cr}$ VI toxicity. Hence, consideration plant extracts like Cucumis melo L. fruits have been used in our current study. This plant extract is vital for regulating the antioxidant and antihyperlipidemic activity. Therefore, the aim of the present study was to investigate the possible antihyperlipidemic activity of Cucumis melo L. whole fruit aqueous extract in $\mathrm{Cr}$ VI induced in rats. Treatment with fruit aqueous extract showed significant $(\mathrm{P}<0.001)$ increased in the level of lipid profile like total cholesterol (TC), triglyceride (TG), low density lipoprotein cholesterol (LDL-C), very low-density lipoprotein cholesterol (VLDL-C) level and reduction in the high-density lipoprotein cholesterol (HDL-C) levels in 49 days treatment when compared to the control animal. Administration of aqueous extract of fruit extracts at a dose of $500 \mathrm{mg} / \mathrm{kg}$ showed higher antihyperlipidemic activity as compared to their respective groups. The results concluded that Cucumis melo $\mathrm{L}$ whole fruit aqueous extract have potent antihyperlipidemic activity via the regulation of cellular homeostasis in Cr VI induced male albino rats.
\end{abstract}

Keywords: Chromium VI, Lipid Profiles, Cucumis melo L fruit extracts, antihyperlipidemic activity

\section{INTRODUCTION}

Heavy metals have been discovered to play a significant role in global environmental pollution. These metals are widely released into the atmosphere as a result of the extraction of metals from their ores for minerals. Since, heavy metals are extremely mobile in the environment, processing these minerals for future usage in various sectors which results in environmental cues. They are non-biodegradable substances that tend to build up in the environment [1]. When they are created in the soil and water bodies and they pose a hazard to human health by affecting their integral organ. The current article to focus on the chromium VI/hexavalent chromium. Therefore, the massive amounts of chromium (Cr) compounds have been released into the environment as a result of widespread industrial use of the metal. The oxidation states of $\mathrm{Cr}$ are primarily consisting in the two forms such as trivalent forms(I) $(\mathrm{Cr}(\mathrm{III}))$ has a high proclivity for forming coordination compounds, is thermodynamically stable, and is found in all biological systems as the ultimate oxidative state and another one is (II) hexavalent form $(\mathrm{Cr}(\mathrm{VI}))$, which is connected to oxygen and is an rendering the toxic materials[2]. The highest exposure to $\mathrm{Cr}(\mathrm{VI})$ compounds in the chromate manufacture, chrome plating, ferrochrome production, stainless steel machining and welding, leather tanning industries. Occupational exposure to $\mathrm{Cr}(\mathrm{VI})$ compounds has been linked to an increased risk of lung cancer. [3,4,5].

The Occupational Safety and Health Administration (OSHA) is currently revising existing rules to restrict occupational exposure to hexavalent $\mathrm{Cr}(\mathrm{Cr}(\mathrm{VI}))$ [6]. $\mathrm{Cr}(\mathrm{VI})$-induced cytotoxicity is still a mystery. Transition metals may operate as 


\title{
International Advanced Research Journal in Science, Engineering and Technology
}

\author{
Vol. 8, Issue 8, August 2021
}

DOI: 10.17148/IARJSET.2021.8875

catalysts in the oxidation of biological molecules, according to research. Therefore, their toxicity is associated withoxidative damage [7]. The Cr(VI) compounds are easily absorbed, can diffuse across cellmembranes, and have strong oxidative potential.Previous literature hasdescribed that hexavalent chromium may increases ROS concentration and followed by inducing lipid peroxidation, which further to exiting the injuries ofhepatocytes and renal cells [8]. Moreover, long-term exposure to large doses of $\mathrm{Cr}$ (VI) may inbuilt the increasestriglycerides, total cholesterol, and other lipoproteins [8].

Hyperlipidemia is a group of disorders distinguished by elevated levels of free fatty acids, predominant triglycerides (TGs), low-density lipoprotein-cholesterol, and decreased plasma high-density lipoprotein (HDL)-cholesterol concentration (good cholesterol)[9]. Hyperlipidemia is the world's fastest growing disease. Nowadays, various man-made drugs are commercially available to control diabetes and hyperlipidemia; however, these man-made drugs come with a slew of side effects, negative effects, and a hefty price tag. Herbal materials and herbal extracts are alternative therapies that have fewer side effects, are less toxic, and are less expensive. Herbals and herbal derivatives contain wide-ranging phytochemicals responsible forantihyperlipidemic activities, identical to alkaloids, flavonoids, glycosides, etc[10].

The fruit is mostly used as a vegetable, and it has sufficient amounts of all important components to serve as a viable human food source. Cucumismelo L. is a climbing herb in the Cucurbitacae family. This plant is commonly known as "Wild melon," and it is native to Asia and Central Africa, as well as Australia, China, and, India, Bangladesh, Tropical Asia and Africa. It is one of the medicinal herbs in the traditional practice of Indian medicine[11].Cucumis melo L. is under the family of Cucurbitaceae, this aromaticplant is normally global in countryside and seaside areas. This aromatic plant is commonly called as wild musk melon, kachari, small guard [12].The present work is desire to investigate the hypolipidemic effect of herbalplantbased drug in countering hyperlipidemia. Hence by using natural plant extract reported to possess antihyperlipidemic activity could be a better alternative to allopathic drugs and hence to prevent $\mathrm{Cr} \mathrm{VI}$ associated toxicity.Therefore, present study was undertaken to investigate the antihyperlipidemic activity of theaqueous fruit extract of Cucumis melo L. in chromium VI induced toxicity in male albino rats.

\section{COLLECTION AND AUTHENTICATION OF PLANT}

\section{MATERIALS \& METHOD}

Cucumis melo L. fruits were collected from vandavasi, Thiruvannamalai, District, Tamil Nadu. All plant materials were collected from the months of December to January 2019-2020. Fruits were authenticated by the Siddha Central Research Institute, Chennai (Central Council for Research in Ayurveda and Siddha, New Delhi, Under the Ministry of Health \& Family Welfare, Govt. of India), Reference No: C14022001M.

\section{PREPARATION OF PLANT EXTRACT}

Extraction was carried out at room temperature under normal conditions. About $5 \mathrm{~g}$ of shade dried powder of fruits of Cucumis melo L. was successively extracted with Aqueous then kept in boiling water bath for 30 minutes. The extract was filtered through whatmann No.1 filter paper under reduced pressure. The extract obtained was filtered, concentrated by heating at $100^{\circ} \mathrm{C}$ in a water bath.

\section{POTASSIUM DICHROMATE $\left(\mathrm{K}_{2} \mathrm{Cr}_{2} \mathrm{O}_{7}\right)$}

It is common inorganic odourless, bright redorange water soluble crystalline powder and waspurchased from scientific Lab Chemicals, Chennai.

\section{ANIMAL AND MAINTENANCE CONDITION}

Male albino rats ranging in body weight from 160 - $180 \mathrm{~g}$ were obtained from the Biomedical Research Unit and Laboratory Animal Centre, BRILAC/SDCH/SIMATS/IAEC/3-2020/049 Chennai and maintained according to the guidelines of CPCSEA under the supervision of Animal Ethical Committee. . All animals were housed under standard conditions $\left(25 \pm 1{ }^{\circ} \mathrm{C}, 12 \mathrm{~h} \mathrm{light} / 12 \mathrm{~h}\right.$ dark cycle $)$ with food and water ad libitum and were acclimated to the laboratory conditions for 7 days prior to starting the experiment.

\section{EXPERIMENTAL DESIGN:}

Male albino rats were divided into eight groups; each group consists of six animals $(n=6)$. Group I served as a control and was given only clean drinking water. Group II was administered with potassium dichromate $10 \mathrm{mg} / \mathrm{kg}$ for 42 days. Group III, IV, V, VI, VII \& VIII were administered with $500 \mathrm{mg} / \mathrm{kg}$ of Cucumis melo L Ascorbic acid and Cucumis melo L along with ascorbic acid, respectively.

Group I - Control

Group II - Potassium dichromate $10 \mathrm{mg} / \mathrm{kg}$ for 42 days

Group III - Ascorbic acid $500 \mathrm{mg} / \mathrm{kg}$ for 7 days

Group IV - Potassium dichromate (10 mg/kg for 42 days) + Ascorbic acid $500 \mathrm{mg} / \mathrm{kg}$ for 7 days

Group V - Potassium dichromate $(10 \mathrm{mg} / \mathrm{kg}$ for 42 days $)+$ Ascorbic acid + Cucumis melo L $500 \mathrm{mg} / \mathrm{kg}$ for $7 \mathrm{days}$

Group VI - Potassium dichromate (10 mg/kg for 42 days) + Cucumis melo L $500 \mathrm{mg} / \mathrm{kg}$ for 7 days

Group VII - Ascorbic acid + Cucumis melo L $500 \mathrm{mg} / \mathrm{kg}$ for 7 days $500 \mathrm{mg} / \mathrm{kg}$ for 7 days

Group VIII - Cucumis melo L $500 \mathrm{mg} / \mathrm{kg}$ for 7 days $500 \mathrm{mg} / \mathrm{kg}$ for 7 days 
Vol. 8, Issue 8, August 2021

DOI: $10.17148 /$ IARJSET.2021.8875

Body weight of all the animals was recorded during 0th, $10^{\text {th }}, 20^{\text {th }}, 30^{\text {th }}, 42^{\text {nd }}$ and $49^{\text {th }}$ days respectively.

\section{HYDROXYL RADICAL (. OH) SCAVENGING ACTIVITY}

Hydroxyl radical scavenging activity was determined by method as described by Halliwell et al., (1987).

\section{Lipid profile}

The lipid profile of animals was determined by collecting the blood from the retro-orbital route of chromium induced animals. The blood was centrifuged at $4000 \times \mathrm{g}$ for $15 \mathrm{~min}$ to collect the serum and analyzed using enzymatic diagnostic kits from Agappe Diagnostic Ltd (Kerala, India). The serum was analyzed for lipid profiles such as total cholesterol [13, 14] triglyceride (TG) [15,16] and highdensity lipoprotein (HDL) [17]. However, low-density lipoprotein and very lowdensity lipoprotein (VLDL) cholesterol were also determined using the Friedewald formula, i.e., LDL cholesterol $=$ total cholesterol - (HDL + VLDL) [18].

\section{STATISTICAL ANALYSIS}

Data were analyzed using statistical software package version (SPSS) 7.0. Student's t-test was used to ascertain the significance of variations between male albino rats. All data were presented as mean $\pm S D$ of $n=6$. Differences were considered significant at $\mathrm{p}<0.05, \mathrm{p}<0.01$ and $\mathrm{p}<0.001$.

\section{RESULTS AND DISCUSSION}

Figure 1: Standardization of ethanolic, chloroformand aqueous extract of Cucumismelo L. by DPPH scavenging activity:

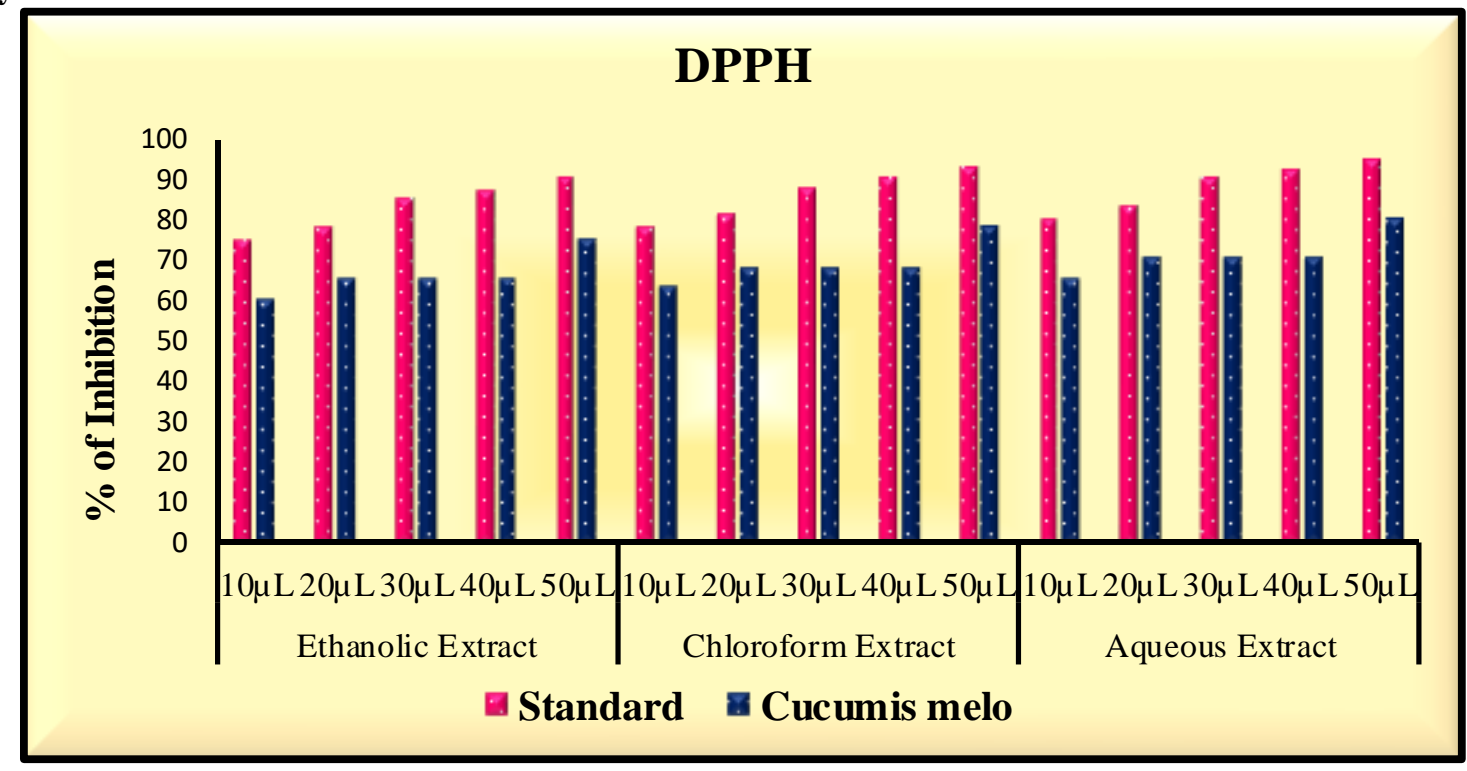

DPPH is a stable free radical whose absorbance at $517 \mathrm{~nm}$ decreases when antioxidants donate protons to DPPH. The ability of DPPHreacts with antioxidants and gets converted into 1,1-diphenyl-2-picryl hydrazine. Quantitative analysis revealed strong DPPH• radical scavenging ability in comparing with ethanolic,chloroform and aqueous extracts of Cucumismelo L. In this study revealed that the comparison of scavenging activity of free radicals was exhibited in Figure 1. Hence the study results depict that the $50 \mu \mathrm{l} / \mathrm{ml}$ of aqueous extract of Cucumis melo L. is most potential activity for reducing the free radical induced toxicity when compared with ethanolic and chloroform extracts of Cucumismelo L. by DPPH method as compared to standard. 
Figure 2: Changes in Total Cholesterol (TC) of rats treated with PDC/Chromium VI, Cucumis melo L and Ascorbic acid

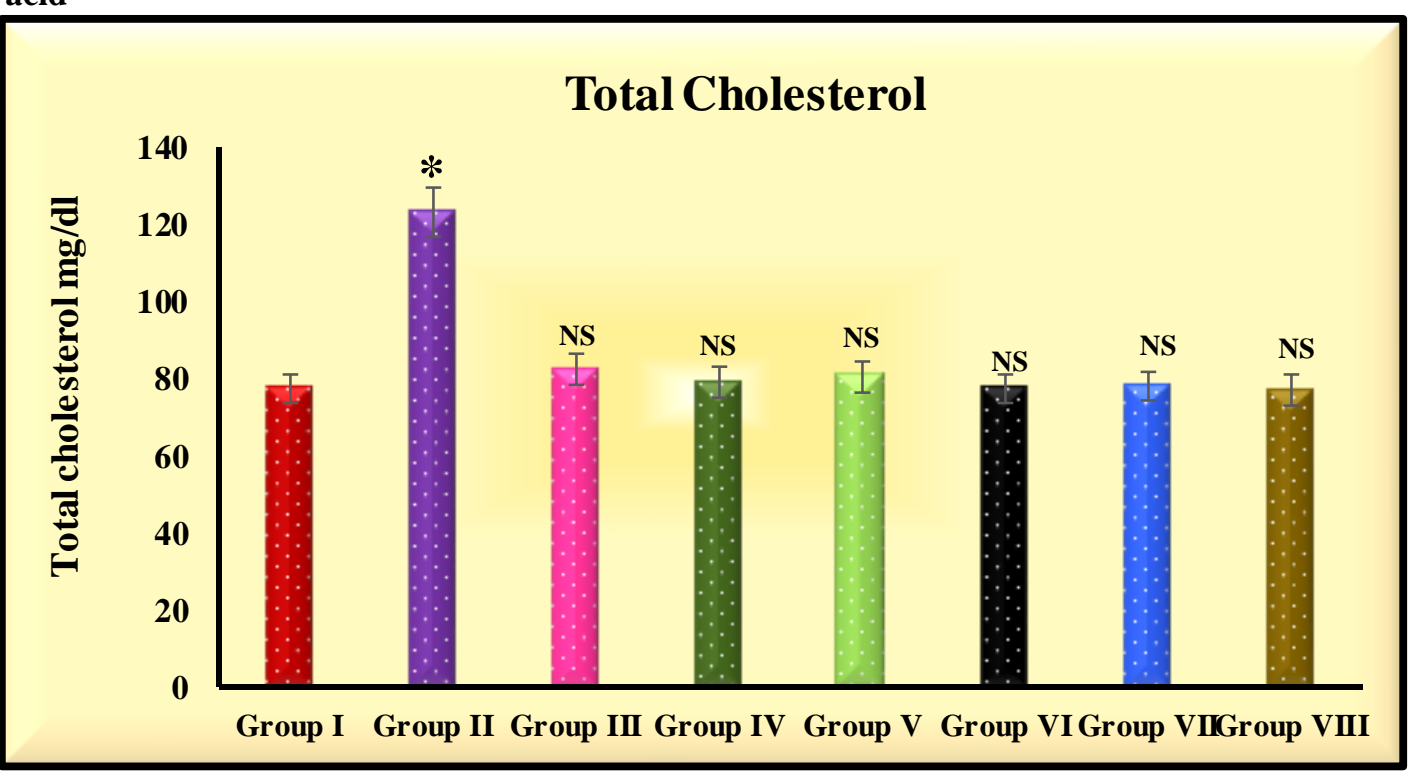

To assess the level of TCtreatment with PDC toxicity, Ascorbic acid and aqueous extract of 500mg of Cucumis melo Lfruit extracts depicts in the Figure 2. The level of TC was significantly increased by 59\% in PDC induced rats when compared with control rats. Subsequently treatment with PDC induced rats along with Ascorbic acid the level of TC was insignificantly increased by $6 \%$ when compared with control rats. Indeed, treatment with PDC induced rats along with Cucumis melo Lfruit extracts depicts the level of TC was insignificantly increased by $2 \%$ when compared with control rats. Afterwards treatment with PDC toxicity, Ascorbic acid and Cucumis melo Lfruit extracts the level of TC was insignificantly increased by $4 \%$ when compared with control animal. Finally determine the 500mg of Ascorbic acid, 500mg of Cucumis melo Lfruit extracts and equal concentration of Ascorbic acid along with Cucumis melo Lfruit extracts depicts the there is no significant changes in total cholesterol. Hence it is confirmed that fruits extracts are equal to modify the lipid profiles and it was mimicking the control rats.

Figure 3: Changes in Triglycerides (TG) of rats treated with PDC/Chromium VI, Cucumis melo L and Ascorbic acid

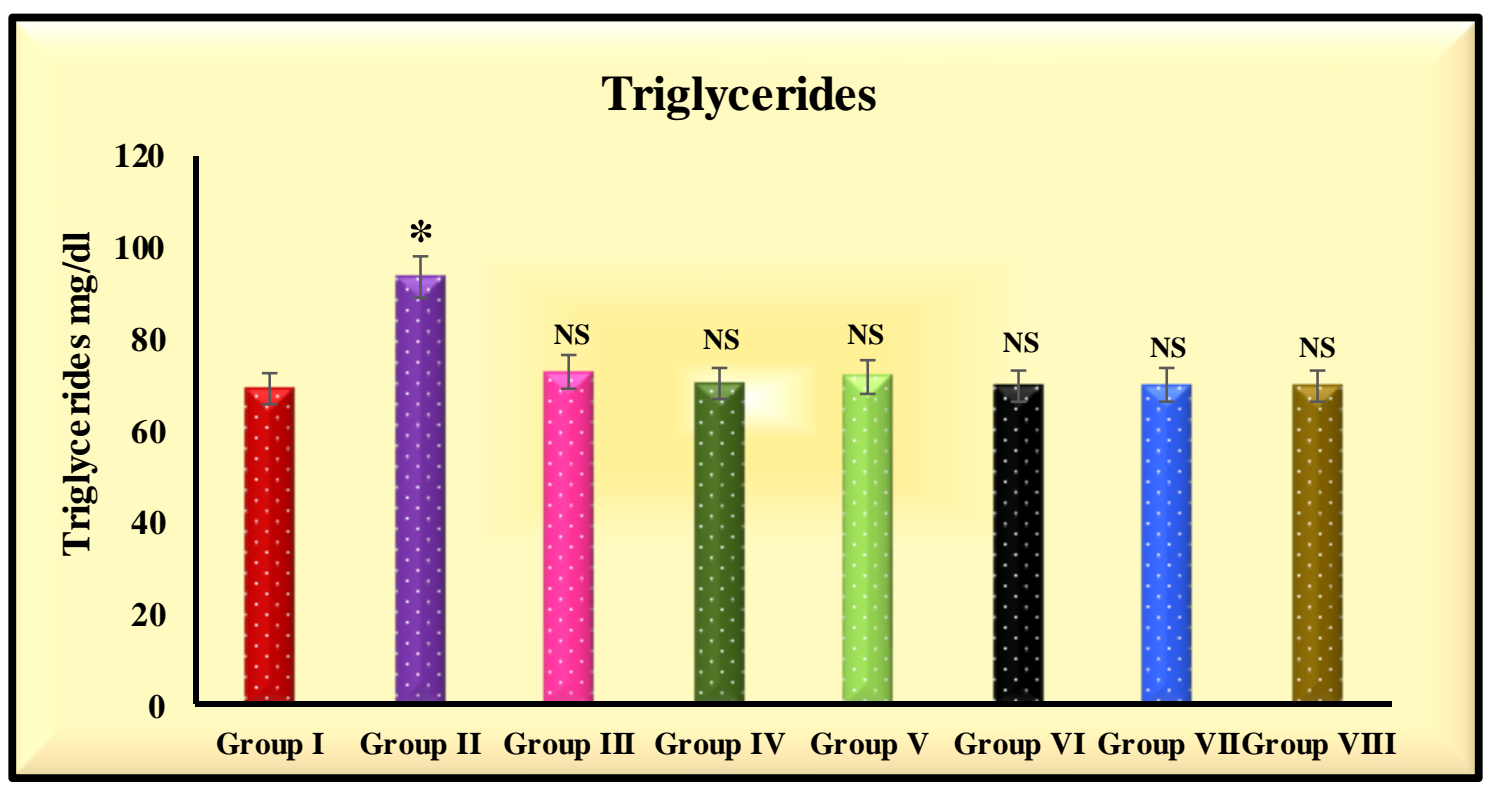

To determinethe level of TG treatment with PDC toxicity, Ascorbic acid and aqueous extract of 500mg of Cucumis melo Lfruit extracts depicts in the Figure 3. The level of TG was significantly increased by $35 \%$ in PDC induced rats when 
Vol. 8, Issue 8, August 2021

\section{DOI: $10.17148 /$ IARJSET.2021.8875}

compared with control rats. Subsequently treatment with PDC induced rats along with Ascorbic acid the level of TG was insignificantly increased by $5 \%$ when compared with control rats. Indeed, treatment with PDC induced rats along with Cucumis melo Lfruit extracts depicts the level of TG was insignificantly increased by $2 \%$ when compared with control rats. Afterwards treatment with PDC toxicity, Ascorbic acid and Cucumis melo Lfruit extracts the level of TG was insignificantly increased by $4 \%$ when compared with control animal. Then, finally quantify the 500mg of Ascorbic acid, $500 \mathrm{mg}$ of Cucumis melo Lfruit extracts and equal concentration of Ascorbic acid along with Cucumis melo Lfruit extracts depicts that the there is no significant changes in level of TG. Hence it is confirmed that fruits extracts can rectify the oxidative stress induced cell damage and it was similar effect when compared with control animals.

Figure 4: Changes in high density lipoprotein (HDL) of rats treated with PDC/Chromium VI, Cucumis melo L and Ascorbic acid

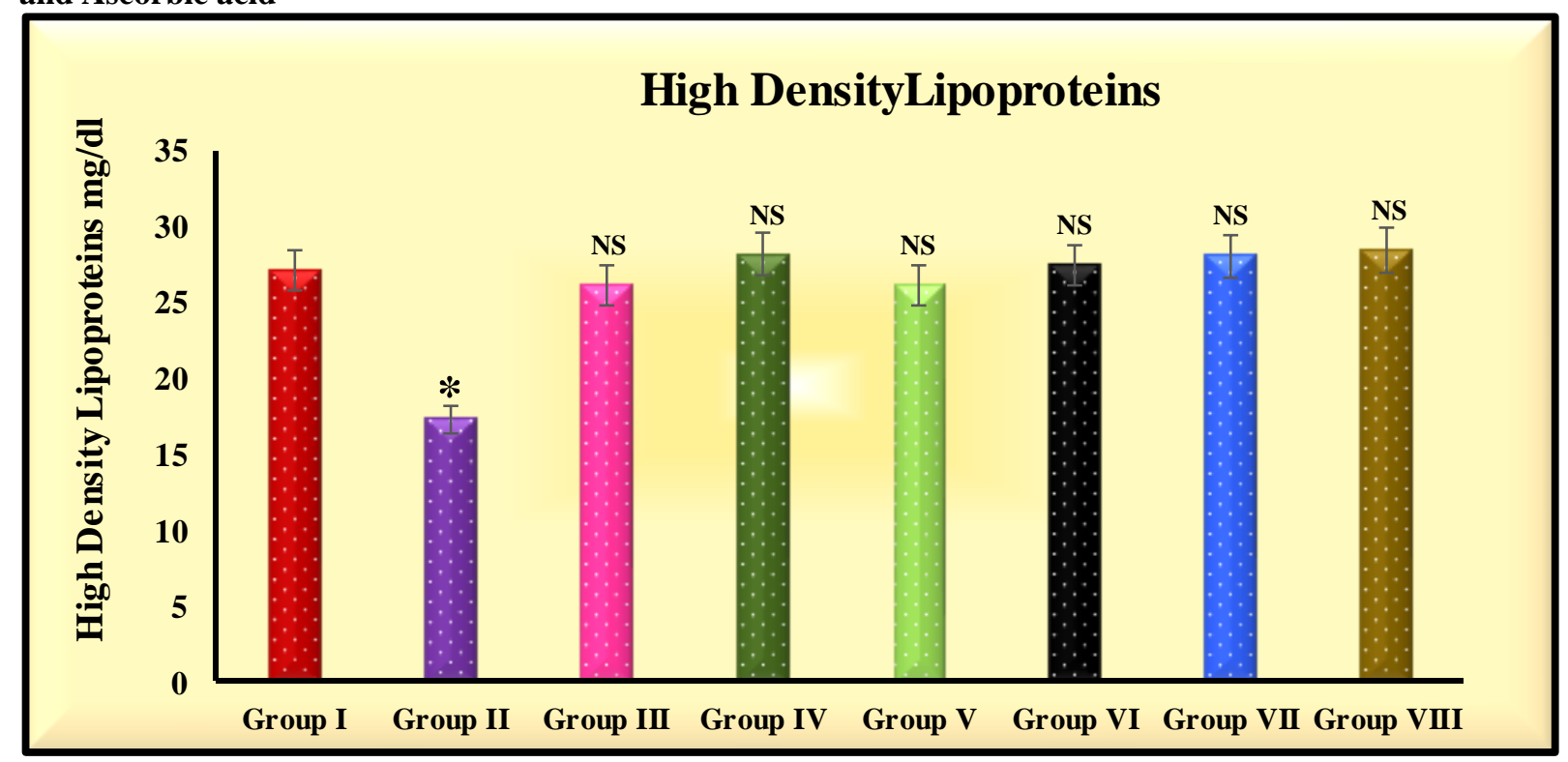

To quantifythe level of HDL treatment with PDC toxicity, Ascorbic acid and aqueous extract of 500mg of Cucumis melo Lfruit extracts depicts in the Figure 4. The level of HDL was decreased by $36 \%$ in PDC induced rats when compared with control rats. Subsequently treatment with PDC induced rats along with Ascorbic acid the level of HDLwas insignificantly decreased by $3 \%$ when compared with control rats. Indeed, treatment with PDC induced rats along with Cucumis melo Lfruit extracts depicts the level of HDL was decreased by $4 \%$ when compared with control rats. Afterwards treatment with PDC toxicity, Ascorbic acid and Cucumis melo Lfruit extracts the level of HDLwas insignificantly decreased by $4 \%$ when compared with control animal and there is no significant changes in the level of HDL was treated with Ascorbic acid, Cucumis melo Lfruit extracts and combined Ascorbic acid, Cucumis melo Lfruit extracts which was mimicking the control animals.

Figure 5: Changes in low density lipoprotein (LDL) of rats treated with PDC/Chromium VI, Cucumis melo L and Ascorbic acid 
DOI: $10.17148 / I A R J S E T .2021 .8875$

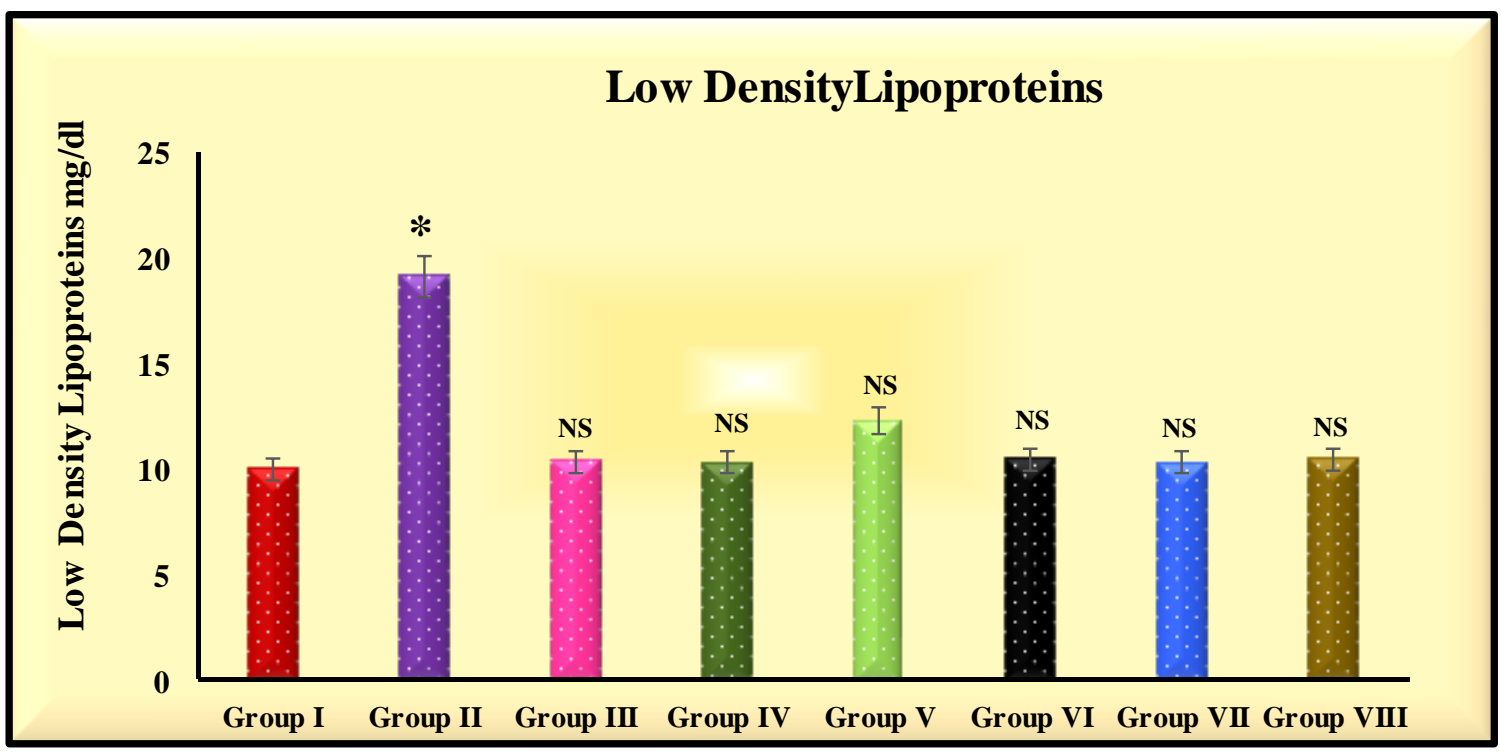

To evaluatethe level of LDL treatment with PDC toxicity, Ascorbic acid and aqueous extract of 500mg of Cucumis melo Lfruit extracts depicts in the Figure 5. The level of LDL was significantly increased by 91\%in PDC induced rats when compared with control rats. Subsequently treatment with PDC induced rats along with Ascorbic acid the level of was insignificantly increased by $4 \%$ when compared with control rats. Indeed, treatment with PDC induced rats along with Cucumis melo Lfruit extracts depicts the level of LDL was insignificantly increased by $3 \%$ when compared with control rats. Afterwards treatment with PDC toxicity, Ascorbic acid and Cucumis melo Lfruit extracts the level of LDL was insignificantly increased by $23 \%$ when compared with control animal. Then quantify the alone Ascorbic acid, Cucumis melo Lfruit extracts and equal concentration of Ascorbic acid along with Cucumis melo Lfruit extracts depicts the there is no significant changes in LDL, which was directly mimicking the control animals.

Figure 6: Changes in very low-density lipoprotein (VLDL) of rats treated with PDC/Chromium VI, Cucumis melo $L$ and Ascorbic acid

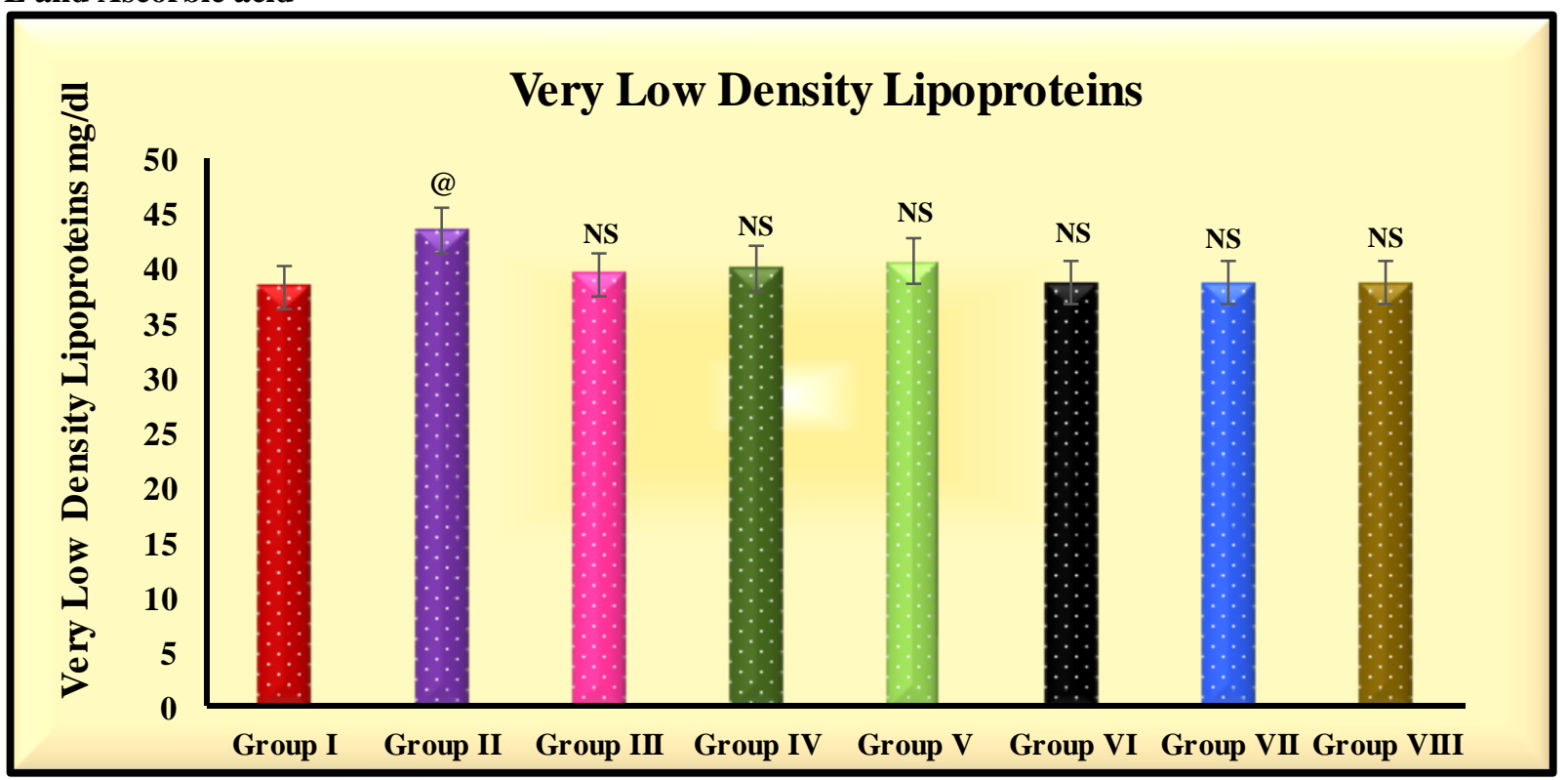

To analysethe level of VLDL treatment with PDC toxicity, Ascorbic acid and aqueous extract of 500mg of Cucumis melo Lfruit extracts depicts in the Figure 6. The level of VLDL was significantly increased by $14 \%$ in PDC induced rats when compared with control rats. Subsequently treatment with PDC induced rats along with Ascorbic acid the level of VLDLwas insignificantly increased by $3 \%$ when compared with control rats. Indeed, treatment with PDC induced rats along with Cucumis melo Lfruit extracts depicts the level of VLDLwas insignificantly increased by $4 \%$ when compared with control rats. Afterwards treatment with PDC toxicity, Ascorbic acid and Cucumis melo Lfruit extracts the level of VLDLwas insignificantly increased by $6 \%$ when compared with control animal. Finally determine the 500mg of Ascorbic 


\section{DOI: 10.17148/IARJSET.2021.8875}

acid, 500mg of Cucumis melo Lfruit extracts and equal concentration of Ascorbic acid along with Cucumis melo Lfruit extracts depicts the there is no significant changes in lipid profiles. Hence it is confirmed that fruits extracts are equal to modify the lipid profiles and it was mimicking the control rats.

The present research work to investigate the efficacy of Cucumis melo L can modulate the lipid profiles on Cr VI toxicity induced male albino rats. Hence standardization of Cucumis melo L was evaluated by the method of DPPH scavenging activity. Therefore, during estimation, the reduction of the DPPH radical to hydrazine as a consequence of the antiradical activity of the Cucumis melo L fruit extracts.Theresults of the DPPH assay suggest that extracts are capable of scavenging free radicals via electron/hydrogen-donating mechanisms. Moreover, DPPH activity of these plants phytonutrients showedsimilar antioxidant, anti-inflammatory and antihyperlipidemic activity[19,20,21] by enriching of polyphenols, ortho-diphenols, flavonoids, and tannins content, thus may indicatingthat radical scavenging capacity of fruit aqueous extracts, which is related to the amount of total phenolic compounds.Hence, the elucidation of ethanolic, chloroform and aqueous extracts is used to determine the DPPHof Cucumis melo L. fruit extracts at various concentration such as $10 \mu \mathrm{L}$, $20 \mu \mathrm{L}, 30 \mu \mathrm{L}, 40 \mu \mathrm{L}$ and $50 \mu \mathrm{L}$. The end of the results indicates that $50 \mu \mathrm{L}$ of aqueous extracts is most effective to quenching the free radicals induced oxidative stress. Indeed, we confirmed that $50 \mu \mathrm{L}$ of aqueous extracts of Cucumismelo L. fruit extracts is beneficial effect when compared with other ethanolic and chloroform extracts. Some author reported that antioxidant activity of Cucumis melo plant extract may be attributed to the high level of total phenolic contents and total flavonoid. This effective plant extracts and their phytoconstituents have antioxidant activities, these antioxidants may act as free radical scavengers by preventing and repairing damages caused by ROS affiliated with various diseases [22]. Hence our present article to discuss about the aqueous extracts of Cucumis melo L has a free radical scavenging activity and that may be due to the presence of secondary metabolites like phenols and flavonoids which are responsible for antioxidant activity in the plant fruits extract.

\section{LIPID PROFILES}

The formation of cell membrane and regulation of several hormones is carried out by the lipids and it is also necessary for other cellular functions. The versatile forms of lipids cannot fade out in the blood and must be transported to and from the cells by low density and high-density lipoproteins. High density lipoprotein cholesterol (HDL-C) tends to carry cholesterol away from arteries back to the liver. Therefore, high level of serum cholesterol may be cause of hepatic injury [23]. Our present study results to depicts the high levels of TC, LDL, VLDL, TG and reduced in serum HDL were significantly expressed in $\mathrm{P}<0.001$ andP $<0.05$ in hexavalent chromium induced toxicity on male albino rats. Here, Amrita et al., [23] also suggested that both nickel and chromium induced high level of serum TC, LDL-C, VLDL-C and TG and fall in serum HDL-C [24] This may be due to the changes in gene expression of some hepatic enzyme like HMG-CoA reductase (hydroxyl-methyl-glutaryl-CoA), which in turn lowers the LDL-receptor gene expression [25,26]. The enhancement of TG is possible due to the hypoactivity of lipoprotein lipase in blood stream which can be able to breaks up the TG. In agreement with this author Terasawa et al., [27] has reported that enhancement of TG along with reduced absorption of fatty acids by adipose tissue is affiliated with decreased quantity of HDL, insulin resistance and which may be an increased risk of atherosclerosis disorders. Coherently, increased level of serum total cholesterol in PDC toxic condition may also be due to the decreased activity of enzymes like cytochrome P450 [28]. The resent results indicated that raise of haematological parameters may also because of increased lipolysis, which regulated by high levels of norepinephrine release which may act via interference with the $\mathrm{Ca}^{+2}$ functions in the cytoplasm [29]. Here, Amrita et al., [23] has portrayed that the hexavalent chromium higher toxicity is converted into the trivalent form this may be due to their higher penetrating power into the cells as it subsists as tetrahedral chromate anion is corresponding tothe formation of others natural anions. Furthermore, once taken into the cell of this hexavalent chromium (PDC) undergoes reduction to chromium (III) involving intracellular glutathione (Wiegand et al., 1984) along with vitamin E in all tissues [30]. All these sequences may regulate the cause of ROS included oxidative/nitrative stress, these inbuilt free radicals may able to damage the functioning of intramolecular metabolism.

Hence our present study to recommend the natural remedy like Cucumis melo L (aqueous fruits extracts of $500 \mathrm{mg} / \mathrm{kg}$ of body weight) plays a vital role for reducing the TC by $57 \%$, TG by $33 \%$, LDL by $88 \%$, VLDL by $10 \%$ and rise in HDL by $32 \%$ levels on PDC (hexavalent chromium) induced male albino rats. Here, some author reported that hyperlipidemic rats were treated with the two different solvents (methanolic and aqueous) at different doses (250 mg/kg and 500mg/kg) may exhibit the significant reduced the levels of serum TG, TC, LDLand VLDL and significant increase in the level of serum HDL-C. Therefore, a significant alteration in these lipid profiles on the hyperlipidemic rats as compared to control animal, which indicates the efficacy of fruit extracts can be controlling the serum lipidmetabolism under these hyperlipidemic conditions. Coherently, Jayant et al., [31] has reported that biochemical estimations had depicted that Cucumis melo methanolic extract $(500 \mathrm{mg} / \mathrm{kg})$ significantly raises the protective HDL-C level and reduced atherogenic LDL and VLDL levels. The cholesterol-lowering effect of Cucumis melo fruit peel (CMFP) extracts could be due to an increased excretion of cholesterol and bile acids via theirfecal sterol excretion. Khanna et al., 2002 has portrayed that the possible mechanism of CMFP of both methanolic and aqueous extracts may involve increase of HDL-C, which is imputed 


\title{
International Advanced Research Journal in Science, Engineering and Technology
}

\author{
Vol. 8, Issue 8, August 2021
}

\section{DOI: 10.17148/IARJSET.2021.8875}

to the mobilization of cholesterol from peripheral cells into the liver by the action of Lecithin Cholesterol Oacyltranseferase (LCAT). This enzyme is involved in the transesterification of cholesterol and the maturation of HDL then finally flux of cholesterol from cell membranes into HDL. Hence, we finalized that fruit extracts is able to recover the lipid profile from PDC toxicity induced adverse situation.

\section{CONCLUSION}

The overall results of current research work concluded that aqueous extract of Cucumis melo L. fruit has potentantihyperlipidemic activity and it also having a protective effect against chromium VI induced toxicity in male albino rats.

\section{ACKNOWLEDGMENTS}

The authors are thankful to Sri Akilandeswari Women's College, Wandiwash for providing the necessary support to carry out this research work.

\section{CONFLICT OF INTEREST}

The authors declare no conflict of interest.

\section{REFERENCES}

1. Vhahangwele Masindi; Khathutshelo L; Muedi. (2018). "Environmental Contamination by Heavy Metals". Chepter 7, Intechopen, 115133. 2018, doi.org/10.5772.

2. $\quad$ Bagchi D; Bagchi M; Stohs S, J, "Chromium (VI)- induced oxidative stress, apoptotic cell death and modulation of p53 tumor suppressor gene.” Molecular and Cellular Biochemistry 222, 2001, 149-158. DOI:10.1023/A:1017958028256.

3. JahnabiSaha; Soma Choudhuri; Dipayan Choudhuri. "Effect of Subchronic Exposure to Chromium on Hematological and Biochemical Parameters of Male Albino Rat." Asian Journal of Pharmaceutical and Clinical Research, Vol 10, Issue 5, 2017, 345-348. DOI:10.22159/ajpcr.2017.v10i5.17468.

4. Holmes A. L; Wise S.S; Wise J, P. “Carcinogenicity of hexavalent chromium.” Indian Journal of Medical Research, 128, 2008, 353-372.

5. Salnikow K; Zhitkovich, A. "Genetic and Epigenetic Mechanisms in Metal Carcinogenesis and Cocarcinogenesis: Nickel, Arsenic, and Chromium." Chemical Research in Toxicology, 21, 2008. 28-44. Doi.org/10.1021/tx700198a.

6. Occupational Safety and Health Administration (OSHA). "Revising the notification requirements in the exposure determination; provisions of the hexavalent chromium standards." OSHA Federal Register 75, 2010, 12485-12409.

7. Kazimierz S. Kasprzak. "Oxidative DNA and protein damage in metal-induced toxicity and carcinogenesis." Free Radical in Biology and Medicine, Volume 32, Issue 10, 15 2002, 958-967. Doi.org/10.1016/S0891-5849(02)00809-2.

8. XiaohongLi; ShengwenHe; JianZhou; XiaoliYu; LanhuaLi; YumeiLiu; WanweiLie. "Cr (VI) induces abnormalities in glucose and lipid metabolism through ROS/Nrf2 signaling".Ecotoxicology and Environmental safety, 213, 2021, 1-13. Doi.org/10.1016/j.ecoenv.2021.112320.

9. Kolovou D.G; Anagnostopoulou K.K; Cokkinos D.V." Pathophysiology of dyslipidemia in the metabolic syndrome." Postgraduate Medical Journal, 81, (956), 2005. 358-66. Doi: 10.1136/pgmj.2004.025601.

10. Switi B. G; Krishna M. G; Sandhya, R. M. "Phytochemicals for diabetes management." Pharmaceutical Crops, 5(1) 2014, 11-28. Doi:10.2174/2210290601405010011.

11. Mollik M.A. H; Hassan A, I; Paul T. K; Sintaha M; Khaleque H. N; Noor F. A, et al. "A Survey of Medicinal Plant Usage by Folk Medicinal Practitioners in Two Villages by the Rupsha River in Bagerhat District, Bangladesh.” Am.-Eurasian J. Sustain. Agric. C(C), CC, $2010,1-8$.

12. Shankar K; Singh SK; Kumar D; Varshney S; Gupta A; Rajan S, et al.," Cucumis melo ssp. Agrestis var. Agrestis Ameliorates High Fat Diet Induced Dyslipidemia in Syrian Golden Hamsters and Inhibits Adipogenesis in 3T3-L1 Adipocytes.” Phcog Mag, 11 (4), 2015, 501-10. Doi: 10.4103/0973-1296.172945.

13. Charles C Allain; Lucy S Poon; Cicely S; G Chan; W Richmond; Paul C Fu. "Enzymatic Determination of Total Serum Cholesterol." Clinical Chemistry. Clinical Chemistry, Volume 20, Issue 4, 1974, 470-475. Doi.org/10.1093/clinchem/20.4.470.

14. A. V. Saravanan; P L Ravishankar; Pradeep Kumar; K Rajapandian; V Kalaivani; M Prem Blaisie Rajula. "Estimation of Serum Triglycerides, Serum Cholesterol, Total Protein, IgG Levels in Chronic Periodontitis Affected Elderly Patients: A Cross-Sectional Study.” Int Soc Prev Community Dent, 7(2), 2017, 120-124. Doi: 10.4103/jispcd.JISPCD_36_17.

15. Jacobs N, J; Van Denmark P,J. "Enzymatic determination of serum triglycerides.” Biochem Biophys, 88, 1960, $250-255$.

16. Tietz, N.W. "Fundamentals of Clincial Chemistry." 3rd Edition, W.B. Saunders, Philadelphia. 1987

17. Brustein M; Scolink K; Morfin R. "Estimation of HDL-C.” J Lipid Res, 19, 1970, 583-93.

18. W. T. Friedewald; R .I. Levy; D S Fredrickson. "Estimation of the concentration of low-density lipoprotein cholesterol in plasma, without use of the preparative ultracentrifuge. Comparative Study." Clin Chem. 6, 1972, 499-502.

19. Filomena M. V; Domenico C; Bruna L. "Characterization of Polyphenolic Compounds in Cantaloupe Melon By-Products." Foods, 8, 196, 2019, 1- 10. Doi:10.3390/foods8060196.

20. Sumitra Singh; Bhagwati Dev. “Anti-Inflammatory Activity of Cucumis Melo L. Subsp. Agrestis (Naudin) Pangalo.” IJPSR. Vol. 11(8), 2020, 3819-3823. Doi:10.13040/IJPSR.0975-8232.

21. Arvind Kumar Srivastava; Alok Mukerjee; Abhishek Tripathi. "Antidiabetic and antihyperlipidemic activities of Cucumis melo var. momordica fruit extract on experimental animals." Future Journal of Pharmaceutical Sciences, 6:92, 2020, 1- 9. Doi.org/10.1186/s43094-020-00116-z. 22. Doaa S; Ibrahim; Marwa A.E; Abd El-Maksoud. “Antioxidant and Antidiabetic Activities of Cucumis Melo Var. Flexuosus Leaf Extract." Indian J PhysiolPharmacol, 62(4), 2018, 445-452. 445-452.

23. Amrita Das Gupta; Swastika N. Das; Salim A. Dhundasi; Kusal K. Das. "Effect of Garlic (Allium sativum) on Heavy Metal (Nickel II and ChromiumVI) Induced Alteration of Serum Lipid Profile in Male Albino Rats.” Int J Environ Res Public Health., 5(3), 2008, 147-151. Doi: 10.3390/ijerph2008050020.

24. K. Gopalasatheeskumar; G. Ariharasivakumar; V. K. Kalaichelvan; T. Sengottuvel;, V, Sanish Devan; V. Srividhya. “Antihyperglycemic and antihyperlipidemic activities of wild musk melon (Cucumis melo var. agrestis) in streptozotocin-nicotinamide induced diabetic rats." Chinese Herbal Medicines., 12, 2020, 399-405. Doi.org/10.1016/j.chmed.2020.02.005. 


\section{International Advanced Research Journal in Science, Engineering and Technology}

Vol. 8, Issue 8, August 2021

\section{DOI: $10.17148 /$ IARJSET.2021.8875}

25. Kantola T,; Kivisto K. T; Neuvonen P.J. Grapefruit juice greatly increases serum concentration of lovastatin and lovastatin acid. Clin. Pharmacol. Ther. 63, 1998, 397-402. Doi.org/10.1016/S0009-9236(98)90034-0.

26. Kojima M; Masui T; Nemoto K; Degawa M. Lead nitrate induced development of hypercholesterolemia in rats; Sterol independent gene regulation of hepatic enzymes responsible for cholesterol homeostasis. Toxicol. Lett. 154(1-2), 2004, 35-44. Doi: 10.1016/j.toxlet.2004.06.010.

27. Terasawa Y; Ladha Z; Leonard S. W; Morrow J. D; Newland D; Sanan D, et al. Increased atherosclerosis in hyperlipidemic mice deficient in alpha-tocopherol transfer protein and vitamin E. Proc. Natl. Acad. Sci. U S A. 95, (25), 2000, 13830=13834. Doi:10.1073/pnas.240462697.

28. Witmer C; Faria E; Park HS; Sadrieh N; Yurkow E; Connell S, et al. "In vivo effects of chromium.” Environ. Health. Perspect. 102(3), 1994, 169-76. Doi: 10.1289/ehp.94102s3169.

29. Liu P, S; Lin M, K; "Biphasic effects of chromium compounds on catecholamine secretion from bovine adrenal medullary cells." Toxicology. 117(1), 1997, 45-53. Doi.org/10.1016/S0300-483X(96)03552-4.

30. Chundawat RS, Sood PP. Vitamins deficiency in developing chick during chromium intoxication and protection thereof. Toxicology, 21(12) 2005, 124-131. Doi: 10.1016/j.tox.2005.03.004.

31. Bidkar, Jayant S.; Ghanwat, Dhanaji Dadaso; Bhujbal, Madhuri D.; and Dama, Ganesh Y. "Anti-hyperlipidemic Activity of Cucumis Melo Fruit Peel Extracts in High Cholesterol Diet Induced Hyperlipidemia in Rats," Journal of Complementary and Integrative Medicine, Vol. 9: Iss. 1, 2012, 1-18. Doi: 10.1515/1553-3840.1580.

32. Khanna A. K; Riziv F; Chander R. "Lipid lowering activity of Phyllanthus niruri inhyperlipidemic rats". Journal of Ethnopharmacology. 82(1), 2002 19-22. DOI:10.1016/S0378-8741(02)00136-8.

33. hanna AK, Riziv F, Chander R. Lipid lowering activity of Phyllanthus niruri in

34. hyperlipidemic rats. Journal of Ethnopharmacology. 2002; 82: 19-22.

35. hanna AK, Riziv F, Chander R. Lipid lowering activity of Phyllanthus niruri in

36. hyperlipidemic rats. Journal of Ethnopharmacology. 2002; 82: 19-22.

37. hanna AK, Riziv F, Chander R. Lipid lowering activity of Phyllanthus niruri in

38. hyperlipidemic rats. Journal of Ethnopharmacology. 2002; 82: 19- 